Electronic Physician (ISSN: 2008-5842)

http://www.ephysician.ir

February 2017, Volume: 9, Issue: 2, Pages: 3768-3775, DOI: http://dx.doi.org/10.19082/3768

\title{
Pathogenesis and treatment of post-operative cognitive dysfunction
}

Maria Pappa ${ }^{1}$, Nikolaos Theodosiadis ${ }^{2}$, Andreas Tsounis ${ }^{3}$, Pavlos Sarafis $^{4}$

${ }^{1} 414$ Military Hospital of Special Diseases, Athens, Greece

2401 Military Hospital of Athens, Athens, Greece

${ }^{3}$ Centers for the Prevention of Addictions and Promoting Psychosocial Health of Municipality of Thessaloniki, Thessaloniki, Greece

${ }^{4}$ Nursing Department, Cyprus University of Technology, Limassol, Cyprus

Type of article: Review

\begin{abstract}
Cognitive disorders common in the post-operative period, are the post-operative delirium (POD) and the postoperative cognitive dysfunction (POCD). The Diagnostic and Statistical Manual of Mental Disorders (DSM) does not mention POCD as a separate disease entity, and thus little is known about the pathogenesis of this disorder. The aim of this study was to review, detect and highlight the most important data cited, regarding pathogenesis mechanisms and treatment of the post-operative cognitive dysfunction (POCD). The study was carried out from March 2015 to June 2015. Literature review was achieved by searching a number of bibliographic databases including PubMed, Google Scholar and SCOPUS, surveying published articles from 1955 to 2014. As far as the selection criteria, the material consists of scientific articles published mainly over the last fifteen years, while material published before 2000 was selected because it was considered to be important. This review showed that deficits are observed in one or more discrete areas of the patient's mental state, such as attention, concentration, memory, psychomotor speed and more. This condition is usually developed over a period of more than a week or month after surgery and is more common in elderly patients. Mechanisms that have been proposed to explain this phenomenon are hyperventilation, hypotension, cerebral microemboli and inflammatory mechanisms. Its differential diagnosis will be made mainly from delirium. POCD treatment will first include the exclusion of any other serious diseases that can cause organic psychosyndrome and then focus on the actual symptoms.

Keywords: Memory deterioration, Pathogenesis, Post-operative cognitive dysfunction, Post-operative mental disorder
\end{abstract}

\section{Introduction}

Cognitive disorders in the postoperative period are the post-operative delirium (POD) and the post-operative cognitive dysfunction (POCD). POD is defined as "a clinical situation in which patients think and speak incoherently, are disoriented and show impairment of memory and attention" which is not explained by a medical history of dementia, and influences the ability to focus (1). POCD is defined by a range of changes in neurocognitive patients' condition and behaviour, for weeks or even months after anaesthesia and operation. Usually, these problems concern difficulties in cognitive processes that patients were doing before operation, i.e. to focus on their work. These influence, at various degrees, the patients' quality of life (2-4). Until today many studies have attempted to investigate POCD however the pathophysiology is not completely elucidated and there are many unanswered questions. This review has tried to investigate this phenomenon and to present all developments concerning the treatment of POCD. The specific study was carried out from March 2015 to June 2015. Literature review was achieved by searching a number of bibliographic databases including PubMed, Google Scholar and SCOPUS, surveying published articles from 1955 to 2014. As for the selection criteria, the material consists of scientific articles published mainly over the last fifteen years, while material that was published before 2000 was selected because it was considered to be important.

\section{Corresponding author:}

Dr. Pavlos Sarafis, Nursing Department, Cyprus University of Technology, Limassol, Cyprus.

Tel.: +35725002586, Email: pavlos.sarafis@cut.ac.cy

Received: August 17, 2016, Accepted: January 18, 2017, Published: February 2017

iThenticate screening: January 15, 2017, English editing: February 05, 2017, Quality control: February 09,2017

(C) 2017 The Authors. This is an open access article under the terms of the Creative Commons Attribution-NonCommercialNoDerivs License, which permits use and distribution in any medium, provided the original work is properly cited, the use is non-commercial and no modifications or adaptations are made. 


\section{Discussion}

\subsection{Clinical characteristics of POCD}

The fifth edition of the Diagnostic and Statistical Manual of Mental Disorders (DSM-5) does not mention POCD as a separate disease entity (5). Usually, the persistent cognitive dysfunction, especially in the elderly, is called POCD (6). The International Society of Postoperative Cognitive Dysfunction considers that POCD is developed when postoperatively deficits are observed in a patient in one or more discrete areas of mental state, such as attention, concentration, executive function, memory, visuospatial ability and psychomotor speed (7). This condition usually develops over a period of more than week, or month, and lasts for a long time. The diagnosis requires sensitive preoperatively and post-operatively neuropsychiatric tests (8). The result of this complication is that patients are at risk of losing their jobs or their independence, and furthermore there is a significant reduction in their quality of life (911). In an international multicentre study of POCD (ISPOCD), a decline in memory function in more than one quarter of patients (over 60 years old) undergoing non-cardiac surgery was found, one week after the surgery and in $10 \%$ of these patients after three months. Corresponding studies have shown similar frequencies, with some of them describing cognitive disorders present even one year post operation. Due to the fact that the number of operations (requiring anaesthesia) exceeds 230 million worldwide (12), and due to the increase in the number of operations in patients over 65 years, this age group will undertake the majority of operations after 2020 (13). If these rates and numbers remain stable, we can expect that in a few years, millions elderly patients will be at risk of developing POCD. This fact demonstrates the importance of POCD not only individually, but also in a social level and requires an intensive effort.

\subsection{Pathophysiology and pathogenesis of POCD}

Unfortunately, to date little is known about the pathophysiology and the mechanisms responsible for POCD. The function of the central nervous system (CNS) depends on the adequate supply of oxygen and nutrients, the effective removal of waste products, and the presence of an adequate neurochemical environment. Any drug causing a disorder (e.g. hypoxia, hypoglycaemia) or affecting in any way the metabolic status of the brain and its homeostasis in general, can cause an overall dysfunction that may occur as a postoperative decline in mental ability functions. The mechanisms that occasionally have been proposed to explain the phenomenon will be examined above.

\subsubsection{Hyperventilation}

Significant hypercapnia and cerebral vasoconstriction that may lead in cognitive deficits were caused from hyperventilation. Wollman and Orkin (14), found that extreme hypocapnia during anaesthesia process is correlated with prolonged cognitive dysfunction time for at least 3 to 6 days after hyperventilation. The above finding was very important since hyperventilation was given for a short period while it basically concerned patients who were young. However, other studies were unable to identify any significant effect of hyperventilation in cognitive function (15, 16).

\subsubsection{Hypotension}

Since the first studies that were carried out and tried to explain POCDs (17), the interest was focused on those factors that cause cerebral hypoperfusion and a decreased cerebral flow. The simplest and most common cause for cerebral hypoperfusion is hypotension. It can cause cognitive deficits, and was used by several research groups to investigate the role of cerebral perfusion. Unfortunately, the results of these studies were not strong enough regarding the role of hypotension. Gruvstad et al. (18) found a slight deterioration (as reflected in psychometric tests) in cognitive functions after hypotensive anaesthesia, but this was considered as insignificant regarding pressure changes observed in everyday life. Eckenhoff et al. (19) studied perception and short-term memory, which are considered as important cognitive functions among younger patients, without mentioning difference in the hypotensive group. Elderly hypotensive patients who were examined five days after retropubic prostatectomy showed deterioration in a number of psychomotor tests compared to a group of normal blood pressure patients (20). The premedication that the total of patients took before undergoing spinal or general anaesthesia was hyoscine. A vasoconstrictor for maintaining blood pressure was used in the normotensive group, while the other group patients were allowed to become hypotensive with a mean blood pressure reduction of 56\% (154 - $68 \mathrm{~mm} \mathrm{Hg}$. No significant differences were detected between the groups, while no difference was also observed in their mental function six weeks after the operation. However, a patient in the hypotensive group experienced thrombosis of a coronary artery and succumbed, and two other patients, (one from each group), experienced adverse reactions. Preoperative tests in two patients showed mental deterioration and one patient (from the normal blood pressure group) was excluded due to difficulties in postoperative examination. These changes may have altered the results in this small group of 27 patients. Thompson et al. examined the effects of hypotension in 30 patients who underwent total hip replacement. Mean arterial pressure fell to $50 \mathrm{~mm} \mathrm{Hg}$ in both hypotensive groups (10 patients in each group) using either halothane or sodium nitroprusside. In the third group, blood pressure was maintained between 
normal ranges. Although no effect was observed on the brain, liver or kidney function, in the myocardial function from 1-2 days and 7-8 days after operation, a patient in the hypotensive group was disoriented 24 hours after surgery and nine patients failed to complete the tests as a result of pain, immobility or suppression (21). The potential impact of the prolonged hypotension was not confirmed in these studies, and was not proved as important in the international ISCOPD study (22).

\subsubsection{Cerebral Microemboli}

Cardiopulmonary bypass (CPB) and the surgical field in cardiac surgery are possible sources of microemboli (clots, fat or air bubbles). Furthermore, microemboli can be derived from aortic atherosclerotic plaques during cross clamping and manipulations of the aorta during surgery. A hypothesis was made, that although the occlusion of larger cerebral vessels can cause focal neurological signs, cerebral microemboli could cause minor neurologic deficits associated with postoperative decline in cognitive function (23). Magnetic resonance imaging (MRI) techniques, diffusion-weighted, show that approximately $50 \%$ of patients undergoing coronary artery bypass graft (CABG), develop discrete lesions suggesting microemboli infarcts (24). Post-mortem studies have confirmed the connection between CABG and cerebral microemboli infarcts (25). It has also been demonstrated, using transcranial ultrasound, that in operations where a heart-lung machine was used (as in on-pump CABGs) the likelihood of cerebral microemboli and therefore cerebrovascular lesions are greater than other operations (26). Nevertheless, the correlation between the number and the size of microemboli and cognitive dysfunction is unclear. Several studies have failed to show correlation between the size of the emboli (using transcranial ultrasound), or the extent of the infarct (diffusion- weighted MRI) to post-operative cognitive disorders or delirium after CABG or other cardiac surgery $(24,26)$. In patients undergoing valve replacement, the results are conflicting regarding the relationship between the size of the emboli and the decline in mental function $(27,28)$. Finally, due to the current imaging techniques, damage only larger than $3 \mathrm{~mm}$ diameter can be represented, and it is possible that in future, a correlation between these types of microembolism can be made by imaging techniques. Therefore, microemboli themselves cannot explain the pathophysiology of postoperative decline of the mental status. Techniques that decrease cerebral blood flow during $\mathrm{CPB}$, such as pharmacologic electroencephalogram (EEG) suppression induced with propofol (29) and hypothermic CPB (30), were expected to reduce the volume of cerebral microemboli. However, these methods were not associated with reduced post-operative mental disorders. It is therefore obvious that there must be a cause beyond cerebral microemboli leading to POCD. This explains why POCDs are often found after non-cardiac surgery. Moller et al. (22) describe cognitive dysfunction one week after operation in $26 \%$, and after three months in $10 \%$ of 1,218 patients undergoing cardiothoracic, abdominal or orthopaedic surgery without perioperative hypoxemia or hypotension or any other risk factor. Thus, as elegantly summarized by Hindman (31) "there is an inherent element in surgery or anaesthesia that leads to, or contributes to, acute and chronic POCD, one element that it's not only found in cardiac surgery".

\subsubsection{Inflammatory mechanisms}

It has been documented in several studies that the use of extracorporeal circulation in cardiac surgery induces an extensive systemic inflammatory response associated with the impairment of cognitive function (32). As demonstrated in one study, administration of small doses of ketamine appears to reduce the incidence of POCD in patients who underwent $\mathrm{CABG}$, possibly through the beneficial anti-inflammatory effect of ketamine (33). The extensive inflammatory response in $\mathrm{CABGs}$ was previously considered as being caused by activating the immune system after the contact of blood components with the artificial bypass circuit materials, and injuries during the ischemia/reperfusion process of the heart, lungs and kidneys after extracorporeal circulation $(34,35)$. Also the breakdown or the injury of the blood-brain barrier during CABG could justify the cerebral inflammatory reaction and the subsequent brain injury with the onset of POCD. However, studies in animals undergoing CABG or other surgery, obtained results with similar activation of the inflammatory agent tumor-necrosis factor-a (TNF-a) in both, on and off-pump operations, and furthermore, similar POCD problems (36). Additionally, the fact that the systemic inflammatory reaction is caused not only in extracorporeal heart surgery, was proved in studies that demonstrated that there is no substantial difference in the inflammatory reaction between on and off-pump surgery (37). This and many other similar studies have shown that the systemic inflammatory response is a phenomenon found not only in cardiac surgery but in a large series of surgical operations (38-40). The mechanism by which the inflammatory reaction affects the cognitive function is complex and difficult to understand. By either focusing on the operation or the patient, a common causative factor for the development of POCD is the inflammatory response of the body. Of course in relationship between inflammation and brain tissue damage, it is difficult to discern which one of them is the cause and which the effect. Any tissue injury is generally followed by an inflammatory reaction associated with the activation of the immune system, which can lead to recovery and treatment, but can also lead to further damage. In rat brain, it was experimentally found, that after subarachnoid haemorrhage (41) and after experimental ischemia of the anterior portion of the brain (42), upregulation was caused to cell pathways associated with inflammation, 
such as those represented by the nuclear transcription factor kB. Furthermore, focal cerebral ischemia can be found not only as a result of local inflammatory response, but also to extensive cerebral inflammation (43). Thus, a total inflammatory reaction of the nervous system can be caused by a wide range of brain pathologies, many of them present during the time of the operation. Alternatively it is established that inflammation may lead to cerebral tissue damage and to the consequent impairment of cognitive function. It is documented that a serious systemic inflammatory response may cause multiorgan failure, including the brain, leading to a wide range of clinical consequences that include delirium and septic encephalopathy, with symptoms ranging from mild cognitive deficit to coma by the suppression of EEG activity (44). Histological findings in animals with septic conditions showed perivascular oedema, swelling and rupture of astrocytes and degeneration of neurons, and data that suggest grave damage of the blood-brain barrier and secondary neuronal degeneration (45). Therefore, it could be assumed that the systemic inflammation associated with cardiac surgery can cause multiple organ dysfunctions through inflammatory mechanisms. These reactions also lead to neuronal inflammation and cognitive malfunction. What is interesting is that until today, there is little existent evidence that similar inflammatory response is found in other operations apart from cardiac surgery. The common mechanism believed to play a role in the development of the inflammatory reaction is that of the limited ischemia effect due to sedation. To date, many researchers believe that sedation causes the effect of limited ischemia in the endothelial cells of the brain. The effect of acute hypoxia in endothelial cells has the initial result of endothelial swelling. With reperfusion and re-oxygen supply, active metabolites are produced, and the main pathological consequence from their release is a chemotactic mobilization, leading to the migration of activated neutrophils, which, after activation, agglutinate with endothelial cells. That leads to the development of microthrombi and to the release of potent pressor substances, and ultimately to the full capillary clogging and blood flow obstruction while total blood flow in large vessels has already been restored (no reflow phenomenon) (46, 47, 48). Neutrophils cause damage with their adhesion to the endothelium of the capillaries. More neutrophils adhere to the endothelium of post-capillary venules, causing damage with the secretion of proteolytic enzymes such as elastase, collagenase, $\beta$-glucuronidase, N-Acetyl- $\beta$-glucosaminidase, large quantities of free oxygen radicals, cytokines and leukotrienes, substances which activate or are cytotoxic to the cell arterial wall, to platelets and to polymorphonuclear themselves (49). The above processes, at the cellular level, seem to contribute to a general "injury" of the nervous system during the perioperative period (50). These processes can play a role in the pathogenesis of neurodegenerative diseases such as Alzheimer's disease, multiple sclerosis and AIDS dementia after HIV-1 infection $(51,52)$. Therefore, CNS reactions to systematic inflammatory mediators can lead to a delay of recovery or in long term postoperative dysfunction of CNS (31). Even a seemingly simple answer to systematically inflammatory stimuli such as fever, may be sufficient to lead to the deterioration of the nervous system and trigger off cognitive dysfunction $(31,53,54)$. In conclusion, the body during the perioperative period faces an inflammatory systemic reaction that greatly affects CNS. This effect could explain the ways that POCD is induced.

\subsection{Differential diagnosis}

Differential diagnosis will be made mainly from delirium. Clinical studies distinguish POD from POCD. The DSM5 defines the characteristics required for the diagnosis of delirium (5). These include consciousness disorders, change in cognition, attention disorders and fluctuations in the psycho-emotional state over time. Lipowski first proposed the distinction of delirium in clinical subtypes, based on the level and persistence of locomotor activity (55). The incidence of delirium is between 10 and $55 \%$ in post-operative patients, depending on the type of operation in which the patient was submitted, with a higher rate in orthopaedic operations compared to general surgery (56). Furthermore, the incidence of delirium is considerably higher in elderly patients. It is estimated that up to $50 \%$ of elderly patients suffer from delirium after an operation (57). The impact of POD is significant and dangerous. This has proven to be associated with increased morbidity and mortality and after one year, approaches $40 \%$ (58). Finally the estimated healthcare costs associated with treating delirium is very high (59). The postoperative delirium is mainly characterized by changes in the consciousness and cognition which are observed for a short period after surgery. Cognitive disorders include disorientation in space and time, language difficulties, impairment in learning and memory. The emotional disorders may be apparent, with intermittent and unstable symptoms of anxiety, fear, irritability, anger and depression. The postoperative delirium often has a changing intensity.

\subsection{Treatment}

The treatment of POCDs includes two different approaches: a) Exclusion of any other serious disease that can cause organic psychosyndrome, b) Treatment of the symptoms of POCDs. When treating patients with POCD at home or in hospital, the first concern is the exclusion of other diseases that can mistakenly appear as POCDs. POCDs in elderly patients may be the only clinical sign of a myocardial infarction or a septic syndrome. In these cases, direct 
treatment for the underlying disease must be provided. More often, POCDs are drug or latent infection induced. The meticulous record of the medication that the patient takes, (whether prescribed or not and including herbal medicines) must be made, for identifying potential toxic substances that need to be discontinued or dosage reduced. Latent infections (including urinary tract infections or pneumonia) must, in secondary level, be excluded. Electrolyte disorders, dehydration, endocrine, kidney, liver or neurological diseases need to be investigated with diagnostic tests. It is useful that hypoglycaemia will be excluded with intravenous glucose solution administration and Wernicke encephalopathy with thiamine administration before glucose in alcoholics. The treatment of symptoms of POCDs makes supportive therapy indispensable. Supportive therapy (i.e. sufficient ventilation and oxygenation, haemodynamic support) should be secured to achieve an optimal environment for recovery. Additionally the control of post-operative pain is important, as there is a correlation between higher pain levels and the development of POCD (60). Inpatient care usually requires several non-pharmaceutical interventions. The regular measurement of vital signs and the frequent communication of the health professional team with the patient, ensure that any aberrant behaviour will be recorded immediately, the sleep-wake cycle will be estimated and the intake and output of liquids during 24-hour will be calculated. Mechanical restrictions are often used in aggressive patients with manic symptoms (61). Single-bed rooms help in reducing stimulation. A clock mounted in a prominent position, a calendar and watching the news on television can help reorientation. It can also be helpful providing adequate room light with variations in light intensity in order for the patient to achieve a normal circadian rhythm (62). The assessment of the ability of swallowing may become useful before the start of feeding per os. It is necessary to monitor closely the fluid electrolyte balance and the respiratory and cardiovascular function (63). After recovery, patients might have fragmentary memory recovery and remember events during an episode, which often causes them stress. The ability of recalling facts after the end of the episode varies (64).

\section{Conclusions}

In this review an attempt was made to thoroughly study the phenomenon of POCD on the basis of its pathogenesis. During the recent years POCD is a growing concern for the surgical and the supporting teams. It is now apparent that except POD, elderly patients are especially prone to suffer from POCD. It is also understood that operations in an aging patient population, will raise the incidence of POCD. The early recognition and exclusion of other diseases that can cause organic psychosyndrome play a significant role in the treatment of POCD.

\section{Acknowledgments:}

The present paper was part of a Dissertation in M.Sc. of "Liaison Psychiatry: Integrated care for Physical and Mental Health" which was conducted in the Faculty of Medicine of National and Kapodistrian University of Athens. The researchers would like to sincerely thank Christodoulou Christos, Assistant Professor of Social Medicine, Psychiatry and Neurology.

\section{Conflict of Interest:}

There is no conflict of interest to be declared.

\section{Authors' contributions:}

All authors contributed to this project and article equally. All authors read and approved the final manuscript.

\section{References:}

1) Rudra A, Chatterjee S, Kirtania J, Sengupta S, Moitra G, Sirohia S, et al. Postoperative delirium. Indian J Crit Care Med. 2006; 10(4): 235-40. doi: 10.4103/0972-5229.29842.

2) Blumenthal JA, Mahanna EP, Madden DJ, White WD, Croughwell ND, Newman MF. Methodological issues in the assessment of neuropsychologic function after cardiac surgery. Ann Thorac Surg. 1995; 59(5): 1345-50. doi: 10.1016/0003-4975(95)00055-P. PMID: 7733766.

3) Mackensen GB, Gelb AW. Postoperative cognitive deficits: more questions than answers. Eur J Anaesthesiol. 2004; 21(2): 85-8. doi: 10.1097/00003643-200402000-00001. PMID: 14977337.

4) $\mathrm{Wu} \mathrm{CL}$, Hsu W, Richman JM, Raja SN. Postoperative Cognitive Function as an Outcome of Regional Anesthesia and Analgesia. Reg Anesth Pain Med. 2004; 29(3): 257-68. doi: 10.1097/00115550-20040500000013. PMID: 15138912.

5) American Psychiatric Association. Diagnostic and statistical manual of mental disorders. 5th ed. Arlington, VA: American Psychiatric Publishing; 2013. 
6) Krenk L, Rasmussen LS, Kehlet H. New insights into the pathophysiology of postoperative cognitive dysfunction. Acta Anaesthesiol Scand. 2010; 54(8): 951-6. doi: 10.1111/j.1399-6576.2010.02268. PMID: 20626359.

7) Rasmussen LS, Larsen K, Houx P, Skovgaard LT, Hanning CD, Moller JT. The assessment of postoperative cognitive function. Acta Anaesthesiol Scand. 2001; 45(3): 275-89. doi: 10.1034/j.13996576.2001.045003275.x. PMID: 11207462.

8) Krenk L, Rasmussen LS. Postoperative delirium and postoperative cognitive dysfunction in the elderly what are the differences? Minerva Anestesiol. 2011; 77(7): 742-9. PMID: 21709661.

9) Monk TG, Weldon BC, Garvan CW, Dede DE, Van der Aa MT, Heilman KM, et al. Predictors of Cognitive Dysfunction After Major Noncardiac Surgery. Anesthesiology. 2008; 108(1): 18-30. doi: 10.1097/01.anes.0000296071.19434.1e. PMID: 18156878.

10) Steinmetz J, Christensen KB, Lund T, Lohse N, Rasmussen LS. Long-term Consequences of Postoperative Cognitive Dysfunction. Anesthesiology. 2009; 110(3): 548-55. doi: 10.1097/ALN.0b013e318195b569. PMID: 19225398.

11) Price CC, Garvan CW, Monk TG. Type and Severity of Cognitive Decline in Older Adults after Noncardiac Surgery. Anesthesiology. 2008; 108(1): 8-17. doi: 10.1097/01.anes.0000296072.02527.18. PMID: 18156877, PMCID: PMC2911011.

12) Weiser TG, Regenbogen SE, Thompson KD, Haynes AB, Lipsitz SR, Berry WR, et al. An estimation of the global volume of surgery: a modelling strategy based on available data. Lancet. 2008; 372(9633): 13944. doi: 10.1016/S0140-6736(08)60878-8. PMID: 18582931.

13) Etzioni DA, Liu JH, Maggard MA, Ko CY. The Aging Population and Its Impact on the Surgery Workforce. Ann Surg. 2003; 238(2): 170-7. doi: 10.1097/01.SLA.0000081085.98792.3d. PMID: 12894008, PMCID: PMC1422682.

14) Wollman SB, Orkin LR. Postoperativehuman reaction time and hypocarbia during anaesthesia. Br $\mathrm{J}$ Anaesth. 1968; 40(12): 920-6. doi: 10.1093/bja/40.12.920. PMID: 5710909.

15) Blenkarn GD, Briggs G, Bell J, Sugioka K. Cognitive Function after Hypocapnic Hyperventilation. Anesthesiology. 1972; 37(4): 381-6. doi: 10.1097/00000542-197210000-00004. PMID: 5074717.

16) Murrin KR, Nagarajan TM. Hyperventilation and psychometric testing. A preliminary study. Anaesthesia. 1974; 29(1): 50-8. doi: 10.1111/j.1365-2044.1974.tb00582.x. PMID: 4808805.

17) Bedford P. Adverse cerebral effects of anaesthesia on old people. Lancet. 1955; 266(6884): 259-63. doi: 10.1016/S0140-6736(55)92689-1. PMID: 13243706.

18) Gruvstad M, Kebbon L, Lof BA. Changes in mental functions after induced hypotension. Acta Psychiatr Scand Suppl. 1962; 163(1): 1-112. PMID: 13902478.

19) Eckenhoff JE, Compton JR, Larson A, Davies RM. Assessment of cerebral effects of deliberate hypotension by psychological measurements. The Lancet. 1964; 284(7362): 711-4. doi: 10.1016/S01406736(64)92539-5. PMID: 14193942.

20) Rollason WN, Robertson GS, Cordiner CM, Hall DJ. A comparison of mental function in relation to hypotensive and normotensive anaesthesia in the elderly. $\mathrm{Br} \mathrm{J}$ Anaesth. 1971; 43(6): 561-6. doi: 10.1093/bja/43.6.561. PMID: 5089934.

21) Thompson GE, Miller RD, Stevens WC, Murray WR. Hypotensive Anesthesia for Total Hip Arthroplasty. Anesthesiology. 1978; 48(2): 91-6. doi: 10.1097/00000542-197802000-00003. PMID: 655457.

22) Moller JT, Cluitmans P, Rasmussen LS, Houx P, Rasmussen H, Canet J, et al. Long-term postoperative cognitive dysfunction in the elderly ISPOCD1 study. ISPOCD investigators. International Study of PostOperative Cognitive Dysfunction. Lancet. 1998; 351(9106): 857-61. doi: 10.1016/S0140-6736(97)07382-0. PMID: 9525362.

23) Stump DA, Rogers AT, Hammon JW, Newman SP. Cerebral emboli and cognitive outcome after cardiac surgery. J Cardiothorac Vasc Anesth. 1996; 10(1): 113-8. doi: 10.1016/S1053-0770(96)80186-8. PMID: 8634376.

24) Knipp SC, Matatko N, Wilhelm H, Schlamann M, Thielmann M, Lösch C, et al. Cognitive Outcomes Three Years After Coronary Artery Bypass Surgery: Relation to Diffusion-Weighted Magnetic Resonance Imaging. Ann Thorac Surg. 2008; 85(3): 872-9. doi: 10.1016/j.athoracsur.2007.10.083. PMID: 18291160.

25) Moody DM, Brown WR, Challa VR, Stump DA, Reboussin DM, Legault C. Brain microemboli associated with cardiopulmonary bypass: A histologic and magnetic resonance imaging study. Ann Thorac Surg. 1995; 59(5): 1304-7. doi: 10.1016/0003-4975(95)00057-R. PMID: 7733757.

26) Liu YH, Wang DX, Li LH, Wu XM, Shan GJ, Su Y, et al. The Effects of Cardiopulmonary Bypass on the Number of Cerebral Microemboli and the Incidence of Cognitive Dysfunction After Coronary Artery 
Bypass Graft Surgery. Anesth Analg. 2009; 109(4): 1013-22. doi: 10.1213/ane.0b013e3181aed2bb. PMID: 19762724.

27) Knipp SC, Matatko N, Schlamann M, Wilhelm H, Thielmann M, Forsting M, et al. Small ischemic brain lesions after cardiac valve replacement detected by diffusion-weighted magnetic resonance imaging: relation to neurocognitive function. Eur J Cardiothor Surg. 2005; 28(1): 88-96. doi: 10.1016/j.ejcts.2005.02.043. PMID: 15922616.

28) Barber PA, Hach S, Tippett LJ, Ross L, Merry AF, Milsom P. Cerebral Ischemic Lesions on DiffusionWeighted Imaging Are Associated With Neurocognitive Decline After Cardiac Surgery. Stroke. 2008; 39(5): 1427-33. doi: 10.1161/STROKEAHA.107.502989. PMID: 18323490.

29) Roach GW, Newman MF, Murkin JM, Martzke J, Ruskin A, Li J, et al. Ineffectiveness of burst suppression therapy in mitigating perioperative cerebrovascular dysfunction. Multicenter Study of Perioperative Ischemia (McSPI) Research Group. Anesthesiology. 1999; 90(5): 1255-64. doi: 10.1097/00000542-199905000-00006. PMID: 10319770.

30) Grigore AM, Mathew J, Grocott HP, Reves JG, Blumenthal JA, White WD, et al. Prospective Randomized Trial of Normothermic versus Hypothermic Cardiopulmonary Bypass on Cognitive Function after Coronary Artery Bypass Graft Surgery. Anesthesiology. 2001; 95(5): 1110-9. doi: 10.1097/00000542200111000-00014. PMID: 11684979.

31) Hindman BJ. Emboli, inflammation, and CNS impairment: an overview. Heart Surg Forum. 2002; 5(3): 249-53. PMID: 12538140.

32) Hudetz JA, Gandhi SD, Iqbal Z, Patterson KM, Pagel PS. Elevated postoperative inflammatory biomarkers are associated with short- and medium-term cognitive dysfunction after coronary artery surgery. $\mathrm{J}$ Anesth. 2011; 25(1): 1-9. doi: 10.1007/s00540-010-1042-y. PMID: 21061037.

33) Hudetz JA, Iqbal Z, Gandhi SD, Patterson KM, Byrne AJ, Hudetz AG. Ketamine attenuates post-operative cognitive dysfunction after cardiac surgery. Acta Anaesthesiol Scand. 2009; 53(7): 864-72. doi: 10.1111/j.1399-6576.2009.01978.x. PMID: 19422355.

34) Gao L, Taha R, Gauvin D, Othmen LB, Wang Y, Blaise G. Postoperative Cognitive Dysfunction After Cardiac Surgery. Chest. 2005; 128(5): 3664-70. doi: 10.1378/chest.128.5.3664. PMID: 16304328.

35) Day JR, Taylor KM. The systemic inflammatory response syndrome and cardiopulmonary bypass. Int J Surg. 2005; 3(2): 129-40. doi: 10.1016/j.ijsu.2005.04.002. PMID: 17462274.

36) Jungwirth B, Kellermann K, Qing M, Mackensen GB, Blobner M, Kochs EF. Cerebral tumor necrosis factor $\alpha$ expression and long-term neurocognitive performance after cardiopulmonary bypass in rats. $\mathrm{J}$ Thorac Cardiovasc Surg. 2009; 138(4): 1002-7. doi: 10.1016/j.jtcvs.2009.06.022. PMID: 19660347.

37) Parolari A, Camera M, Alamanni F, Naliato M, Polvani GL, Agrifoglio M, et al. Systemic Inflammation After On-Pump and Off-Pump Coronary Bypass Surgery: A One-Month Follow-Up. Ann Thorac Surg. 2007; 84(3): 823-8. doi: 10.1016/j.athoracsur.2007.04.048. PMID: 17720383.

38) Börgermann J, Scheubel RJ, Simm A, Silber RE, Friedrich I. Inflammatory Response in On- Versus OffPump Myocardial Revascularization: Is ECC Really the Culprit? Thorac Cardiovasc Surg. 2007; 55(8): 473-80. doi: 10.1055/s-2007-965631. PMID: 18027331.

39) Jungwirth B, Eckel B, Blobner M, Kellermann K, Kochs EF, Mackensen GB. The Impact of Cardiopulmonary Bypass on Systemic Interleukin-6 Release, Cerebral Nuclear Factor-kappa B Expression, and Neurocognitive Outcome in Rats. Anesth Analg. 2010; 110(2): 312-20. doi: 10.1213/ANE.0b013e3181bbc42e. PMID: 19861361.

40) Tomic V, Russwurm S, Möller E, Claus RA, Blaess M, Brunkhorst F, et al. Transcriptomic and proteomic patterns of systemic inflammation in on-pump and off-pump coronary artery bypass grafting. Circulation. 2005; 112(19): 2912-20. doi: 10.1161/CIRCULATIONAHA.104.531152. PMID: 16275880.

41) Ma CX, Yin WN, Cai BW, He M, Wu J, Wang JY, et al. Activation of TLR4/NF kappaB signaling pathway in early brain injury after subarachnoid hemorrhage. Neurol Res. 2009. doi: 10.1179/016164109X12445616596283. PMID: 19703340.

42) Clemens JA, Stephenson DT, Smalstig EB, Dixon EP, Little SP. Global Ischemia Activates Nuclear FactorB in Forebrain Neurons of Rats. Stroke. 1997; 28(5): 1073-80. doi: 10.1161/01.STR.28.5.1073. PMID: 9158652.

43) Dhawan J, Benveniste H, Nawrocky M, Smith SD, Biegon A. Transient focal ischemia results in persistent and widespread neuroinflammation and loss of glutamate NMDA receptors. Neuroimage. 2010; 51(2): 599605. doi: 10.1016/j.neuroimage.2010.02.073. PMID: 20206701, PMCID: PMC2856923. 
44) Young G, Bolton C, Archibald Y, Austin T, Wells G. The Electroencephalogram in Sepsis-Associated Encephalopathy. J Clin Neurophysiol. 1992; 9(1): 145-52. doi: 10.1097/00004691-199201000-00016. PMID: 1552002.

45) Davies DC. Blood-brain barrier breakdown and oedema formation in systemic sepsis and human brain tumours. J Anat. 2002; 200(5): 523-34. doi: 10.1046/j.1469-7580.2002.00047_17.x. PMID: 12162731, PMCID: PMC1570705.

46) Kurtel H, Fujimoto K, Zimmerman BJ, Granger DN, Tso P. Ischemia-reperfusion-induced mucosal dysfunction: role of neutrophils. Am J Physiol. 1991; 261(3 Pt 1): G490-6. PMID: 1887895.

47) McMillen MA, Huribal M, Sumpio B. Common pathway of endothelial-leukocyte interaction in shock, ischemia, and reperfusion. Am J Surg. 1993; 166(5): 557-62. doi: 10.1016/S0002-9610(05)81153-5. PMID: 8238752 .

48) Meisel SR, Shapiro H, Radnay J, Neuman Y, Khaskia AR, Gruener N, et al. Increased expression of neutrophil and monocyte adhesion molecules LFA-1 and Mac-1 and their ligand ICAM-1 and VLA-4 throughout the acute phase of myocardial infarction: possible implications for leukocyte aggregation and microvascular plugging. J Am Coll Cardiol. 1998; 31(1): 120-5. doi: 10.1016/S0735-1097(97)00424-5. PMID: 9426029.

49) Korthuis RJ, Smith JK, Carden DL. Hypoxic reperfusion attenuates postischemic microvascular injury. Am J Physiol. 1989; 256(1 Pt 2): H315-9. PMID: 2912194.

50) Allan SM, Rothwell NJ. Cytokines and acute neurodegeneration. Nat Rev Neurosci. 2001; 2(10): 734-44. doi: 10.1038/35094583. PMID: 11584311.

51) González-Scarano F, Baltuch G. Microglia as mediators of inflammatory and degenerative diseases. Annu Rev Neurosci. 1999; 22: 219-40. doi: 10.1146/annurev.neuro.22.1.219. PMID: 10202538.

52) Gahtan E, Overmier JB. Inflammatory pathogenesis in Alzheimer's disease: biological mechanisms and cognitive sequeli. Neurosci Biobehav Rev. 1999; 23(5): 615-33. doi: 10.1016/S0149-7634(98)00058-X. PMID: 10392655.

53) Dietrich WD, Alonso O, Halley M, Busto R. Delayed Posttraumatic Brain Hyperthermia Worsens Outcome after Fluid Percussion Brain Injury: A Light and Electron Microscopic Study in Rats. Neurosurgery. 1996; 38(3): 533-41. PMID: 8837806.

54) Azzimondi G, Bassein L, Nonino F, Fiorani L, Vignatelli L, Re G, et al. Fever in Acute Stroke Worsens Prognosis: A Prospective Study. Stroke. 1995; 26(11): 2040-3. doi: 10.1161/01.STR.26.11.2040. PMID: 7482646.

55) Lipowski ZJ. Transient Cognitive Disorders (Delirium, Acute Confusional Sates) in the Elderly. Am J Psychiatry. 1983; 140(11): 1426-36. doi: 10.1176/ajp.140.11.1426. PMID: 6624987.

56) Michota FA, Frost SD. Perioperative management of the hospitalized patient. Med Clin North Am. 2002; 86(4): 731-48. doi: 10.1016/S0025-7125(02)00020-2. PMID: 12365338.

57) Ansaloni L, Catena F, Chattat R, Fortuna D, Franceschi C, Mascitti P, et al. Risk factors and incidence of postoperative delirium in elderly patients after elective and emergency surgery. Br J Surg. 2010; 97(2): 273-80. doi: 10.1002/bjs.6843. PMID: 20069607.

58) Inouye SK, Zhang Y, Han L, Leo-Summers L, Jones R, Marcantonio E. Recoverable cognitive dysfunction at hospital admission in older persons during acute illness. J Gen Intern Med. 2006; 21(12): 1276-81. doi: 10.1111/j.1525-1497.2006.00613.x. PMID: 16965558, PMCID: PMC1924736.

59) Inouye SK, Ferrucci L. Introduction: Elucidating the Pathophysiology of Delirium and the Interrelationship of Delirium and Dementia. J Gerontol A Biol Sci Med Sci. 2006; 61(12): 1277-80. doi: 10.1093/gerona/61.12.1277. PMID: 17234820, PMCID: PMC2645654.

60) Lynch EP, Lazor MA, Gellis JE, Orav J, Goldman L, Marcantonio ER. The Impact of Postoperative Pain on the Development of Postoperative Delirium. Anesth Analg. 1998; 86(4): 781-5. doi: 10.1213/00000539199804000-00019. PMID: 9539601.

61) Wang W, Wang Y, Wu H, Lei L, Xu S, Shen X, et al. Postoperative Cognitive Dysfunction: Current Developments in Mechanism and Prevention. Med Sci Monit. 2014; 20: 1908-12. doi: 10.12659/MSM.892485. PMID: 25306127, PMCID: PMC4206478.

62) Attard A, Ranjith G, Taylor D. Delirium and its treatment. CNS Drugs. 2008; 22(8): 631-44. doi: 10.2165/00023210-200822080-00002. PMID: 18601302.

63) Joshi S. Current concepts in the management of delirium. Mo Med. 2007; 104(1): 58-62. PMID: 17410827.

64) Kirshner HS. Delirium: a focused review. Curr Neurol Neurosci Rep. 2007; 7(6): 479-82. doi: 10.1007/s11910-007-0074-7. PMID: 17999893. 